\title{
Integrated Reporting in Developing Countries: Evidence from Malawi
}

\author{
Andrew Munthopa Lipunga \\ Department of Accountancy, University of Malawi - The Polytechnic \\ Private Bag 303, Chichiri, Blantyre 3, Malawi \\ E-mail: alipunga@poly.ac.mw
}

Received: March 6, 2014

Accepted: April 15, 2015

Published: April 15, 2015

doi:10.5296/jmr.v7i3.7195

URL: http://dx.doi.org/10.5296/jmr.v7i3.7195

\begin{abstract}
The study investigated the level of Integrated Reporting (IR) in developing countries focusing on Malawi. It employed content analysis using an Integrated Reporting Index (IRI) in examining annual reports of Malawian listed companies. Based on the score range of 0 to 1 being the minimum and maximum respectively, the study revealed an average IRI of 0.43 and consequently an IR gap of 0.57 . The average IRI suggested achievement of some progress toward IR by the companies and on the other hand the IR gap indicates the need for much more effort to be exerted in promoting IR amongst the listed companies in Malawi. Besides, are view of the Malawian IR framework suggested that IR is being governed by a code of corporate governance that lacks detailed guidelines with respect to it hence in need of upgrading of the same.
\end{abstract}

Keywords: Content analysis, Integrated reporting (IR), Integrated Reporting Index (IRI), Integrated Report Gap (IR gap), Malawi 


\section{Introduction}

The modern business community considers information as an influential component in decision-making process(Oprişor 2014). Reporting is thus acrucial aspect of management of companies. Previously financial reporting was considered adequate in meeting the reporting requirements. This was possible because companies were narrowly recognising their stakeholders who were also less demanding and biased towards financial information. The current business environment embraces a broader stakeholder view; as a result the number of recognised stakeholders has greatly increased. Furthermore, the stakeholders are more demanding and not simply biased on financial indicators; they are seeking a balanced overview of the companies' situation(Oprişor 2014). There is pressure for the companies to provide balanced reporting of performance by providing both financial and non-financial information. Although the original intention of non-financial reporting was to provide information of interest to other stakeholders not previously recognised, ironically shareholders are also paying increasing attention to them (Eccles and Saltzman, 2011).

Pressure to provide both financial and non-financial information is also emanating from the very objective of financial reporting of presenting "a true and fair view". Eccles and Saltzman (2011) argued that the "questions about whether a financial report presents a "true and fair view" of a company cannot be adequately answered, because the reports do not contain information on non-financial performance that can determine a company's long-term financial picture'. Basically organisations do not operate in a vacuum, their performance is impacted by the environment; hence the financial figures aiming at representing the performance of the organisations should be given within their operating context to allow the stakeholders make appropriate assessment.

Another reason for increased need for non-financial reporting is based on morality. The current thinking is that organisations are obliged morally to enhance a positive contribution to society (Habidin et al., 2012). This is based on the understanding that organisations exist because society has authorised them to operate, to use resources and to affect the quality of citizens' lives (Ávila et al., 2013). Thus it is expected that corporate reporting should provide insights into how a company views itself and its role in society, communicating company's performance both good and bad and indicating commitments to improve future performance and establish accountability for meeting objectives (Krzus, 2011).

This increased need to improve disclosure of both financial and non-financial information has brought into attention the opportunity to implement a reporting framework called "Integrated Reporting" (Oprişor 2014). According to Abeysekera (2013), Integrated Reporting (IR) attempts to combine the reporting of different facets of organisational activities on a common platform with a unified objective, bringing together all important elements of organisational performance in a single report. At the heart of the IR conceptual framework is the notion that companies should expand their reporting to include all of the resources they use as inputs to their business activities (Cheng et al., 2014). Krzus (2011) posited that the IR practice has potential of enabling stakeholders to fully evaluate the economic, environmental, and social performance of a business in so doing facilitating a more effective assessment of a company's 
ability to create value over the long-term. The IR framework is being seen as an opportunity for reporting formats that focus on single aspect of reporting that work together to achieve a more holistic reporting format about the simultaneous web of interactions and implications of financial, social, environmental, and governance-related organisational activities for stakeholders (Abeysekera, 2013). Thus IR is said to be forming one of the cornerstones of corporate accountability (Krzus, 2011).

Due to the perceived benefits, IR is gaining worldwide acceptance and research interest is growing. However currently there is dearth of empirical studies on the subject worldwide. At the same time, it is being acknowledged that research is in a complex developmental stage which is critical to its development (Oprişor 2014; Eccles and Saltzman, 2011; Cheng et al., 2014). There is therefore need for more studies to facilitate its development generally. Further to that, more often than not, most studies on contemporary corporate reporting issues (such as CSR, corporate governance, risk etc) tend to be carried out in developed countries and far less in developing countries. This tendency leads to little knowledge of the status and of the needed improvements in developing countries, and consequently the reporting frameworks tend to be underdeveloped. This study ensures that developing countries are not left behind. As a result, the study focused on a developing country, Malawi and it examined the annual reports of companies listed on Malawi Stock Exchange (MSE). The study endeavours to create awareness and impetus for IR in Malawi by highlighting the existing gaps in the Malawian IR framework and giving the current IR status by the Malawian listed companies. The study will also assist the preparer of annual reports in aligning them and move in tandem with current reporting trends. The study contributes to extant literature on integrated reporting generally and on current status in developing countries and will act as a reference for future studies. The rest of the paper is structured as follows. Section two presents a review of literature on the development of the integrated reporting framework and the provisions of integrated reporting in Malawi and the gaps thereof, followed by section three that discusses the research methodology. Presentation of results and the ensuing discussion arein section four and the finally section five gives concluding remarks.

\section{Literature review}

\subsection{Integrated reporting}

According to Ioana and Adriana (2013), corporate non-financial reporting has developed from predominately single-issue reports that were mostly environmentally focused, to multi-issue or sustainability reports. Ioana and Adriana (2013) noted that the trend towards multi-issue reporting is going further towards integrated reporting, which they described as "sustainability reporting integrated within the financial or annual report". They then intimated that IR could be one of the major topics in the debate on the future of sustainability reporting. Rightly as they predicted, currently IR is gaining worldwide acceptance as a holistic corporate reporting framework of relevance to the modern environment.

IIRC (2013) defines Integrated Reporting as "a process founded on integrated thinking that results in a periodic integrated report by an organization about value creation over time and related communications regarding aspects of value creation". Churet et al. (2014) noted that 
in its simplest form, IR can be understood as the convergence of the sustainability report and the financial report into a single "narrative" i.e. a communication intended mainly for investors in which top management provides its views on how sustainability issues and initiatives are expected to contribute to the long-term growth strategy of the business. "Integrated thinking" on the other hand is defined as "the active consideration by an organization of the relationships between its various operating and functional units and the capitals that the organization uses or affects" (IIRC, 2013). Dumitru et al. (2013) described integrated thinking further and clearer as "a reflexion of the management's capacity to monitor, manage and disclose the entire complexity of the value creation process and how it contributes to success in time". IIRC (2013) recognises that integrated thinking leads to integrated decision making and actions that consider the creation of value over the short, medium and long term.

The product of the IR process is the production of an "integrated report". IIRC (2013) defines integrated report as "a concise communication about how an organization's strategy, governance, performance and prospects, in the context of its external environment, lead to the creation of value over the short, medium and long term". According to Eccles and Saltzman (2011), an integrated report is not intended simply to be a compendium of every single piece of performance information; on the contrary, it is there to bring together material information on financial and non-financial performance in one place. Furthermore Abeysekera (2013) posited that integrated report should explain the story of reaching the organisation's vision, underpinned by its values, enacted by management, monitored by governance, and using facets of resources relating to financial capital, intellectual capital, social capital, and environmental capital. Besides, it should show the relationships between material, financial and non-financial performance metrics (Eccles and Saltzman, 2011).Thus the report should be capable of promoting a more cohesive and efficient approach to corporate reporting, that aims at improving the quality of information enabling more efficient and productive allocation of capital (IIRC, 2013).

\subsection{International Integrated Reporting Council (IIRC) framework}

The International Integrated Reporting Council (IIRC) was established in 2010 (Cheng et al., 2014). The IIRC is a global coalition of regulators, investors, companies, standard setters, the accounting profession and NGOs with a shared view that the "communication about value creation should be the next step in the evolution of corporate reporting" (IIRC, 2013). The mission of the council is "to enable Integrated Reporting to be embedded into mainstream business practice in the public and private sectors" (http://www.theiirc.org/the-iirc/). Accordingly IIRC issued an Integrated Reporting (IR) Framework in late 2013 (Cheng et al., 2014). Cheng et al. (2014) observed that the Framework allows companies to provide a clear link between the reported non-financial information and the financial information in a manner that allows assessment of the on-going future performance of the company. It is supposed to be implemented by companies through the production of a separate report (i.e. an integrated report) that integrates the companies' financial and non-financial information (Cheng et al., 2014). 


\section{Macrothink Institute $^{\mathrm{TM}}$}

The Framework comprehensively provides general understanding of IR, the IR process and the essential elements that may be included in the presentation of the integrated report. According to IIRC (2013) an integrated report is supposed to depict the following eight elements answering the corresponding questions:

(1) Organizational Overview and External Environment: What does the organization do and what are the circumstances under which it operates?

(2) Governance: How does the organization's governance structure support its ability to create value in the short, medium and long term?

(3) Business Model: What is the organization's business model?

(4) Risks and Opportunities: What are the specific risks and opportunities that affect the organization's ability to create value over the short, medium and long term, and how is the organization dealing with them?

(5) Strategy and Resource Allocation: Where does the organization want to go and how does it intend to get there?

(6) Performance: To what extent has the organization achieved its strategic objectives for the period and what are its outcomes in terms of effects on the capitals?

(7) Outlook: What challenges and uncertainties is the organization likely to encounter in pursuing its strategy, and what are the potential implications for its business model and future performance?

(8) Basis of presentation: How does the organization determine what matters to include in the integrated report and how are such matters quantified or evaluated?

According to the Framework an integrated report has three aims which are to provide insight about:

(1) The external environment that affects an organization.

(2) The resources and the relationships used and affected by the organization. The "resources and relationships" are collectively referred as the "capitals" and are categorized as financial, manufactured, intellectual, human, social and relationship, and natural.

(3) How the organization interacts with the external environment and the capitals to create value over the short, medium and long term.

The integrated report is thus extensive and appears complicated and challenging to implement. However to ensure ease and effective implementation, the IIRC has provided greater flexibility in the preparation and presentation process of the report. For instance, it provides 
that an integrated report may be prepared in response to existing compliance requirements, and may be either a standalone report or be included as a distinguishable, prominent and accessible part of another report or communication(IIRC, 2013) such as an annual report. Furthermore, the framework does not prescribe specific key performance indicators (KPIs), measurement methods or the disclosure of individual matters. Those responsible for the preparation and presentation of the integrated report are expected to exercise judgement, given the specific circumstances of the organization, to determine which matters are material and how they are disclosed, including the application of generally accepted measurement and disclosure methods as is appropriate (IIRC, 2013). The IR Framework also recognises that it is not necessary for an integrated report to include all matters referred to in the guidance (IIRC, 2013); presentation should be made of material matters.

Given flexibility and discretion that is provided, the Framework makes some stipulations to balance discretion with necessary responsibility to ensure integrity of the report. Accordingly, it requires integrated report to include a statement of the following fromthose charged with governance of the company:

- An acknowledgement of their responsibility to ensure the integrity of the integrated report

- An acknowledgement that they have applied their collective mind to the preparation and presentation of the integrated report

- Their opinion or conclusion about whether the integrated report is presented in accordance with this Framework or, if it does not include such a statement, it should explain:

o What role those charged with governance played in its preparation and presentation

o What steps are being taken to include such a statement in future reports

o The time frame for doing so, which should be no later than the organization's third integrated report that references this Framework.

Furthermore, the IR framework is principle based, thus underlying the preparation of an integrated report are the eight guiding principles which according the Framework should inform the content and how the information is presented. They are:

1. Strategic focus and future orientation: An integrated report should provide insight into the organization's strategy, and how it relates to the organization's ability to create value in the short, medium and long term, and to its use of and effects on the capitals 
2. Connectivity of information: An integrated report should show a holistic picture of the combination, interrelatedness and dependencies between the factors that affect the organization's ability to create value over time

3. Stakeholder relationships: An integrated report should provide insight into the nature and quality of the organization's relationships with its key stakeholders, including how and to what extent the organization understands, takes into account and responds to their legitimate needs and interests

4. Materiality: An integrated report should disclose information about matters that substantively affect the organization's ability to create value over the short, medium and long term

5. Conciseness: An integrated report should be concise

6. Reliability and completeness: An integrated report should include all material matters, both positive and negative, in a balanced way and without material error

7. Consistency and comparability: The information in an integrated report should be presented: (a) on a basis that is consistent over time; and (b) in a way that enables comparison with other organizations to the extent it is material to the organization's own ability to create value over time.

\subsection{Benefits of the established IR framework}

According to Krzus (2011) the four critical benefits of IR that are correcting fundamental problems with today's reporting model include: greater clarity; better decisions; deeper engagement; and lower reputational risk. Eccles and Saltzman (2011) classified the benefits to include: internal benefits - involving better internal resource allocation decisions, greater engagement with shareholders and other stakeholders, and lower reputational risk and external market benefits - the ability to meet the needs of mainstream investors who want environmental, social and governance information. Krzus (2011) observed that IR enables the reader to better understand the cause and effect relationships between, for example, financial and sustainability performance. Abeysekera (2013) pointed out that IR facilitates achievement of a more holistic reporting format that reports about the simultaneous web of interactions and implications of financial, social, environmental, and governance-related organisational activities for stakeholders. Technologically, Krzus (2011) noted that IR serves as a platform to furnish more detailed data than what is available only in a paper or PDF report. This enables organisations to leverage on the Internet and Web 2.0 tools and technologies, consequently facilitating the readers' ability not only to perform their own analysis of financial and non-financial information, but also to communicate their thoughts and opinions with other stakeholders. The same is of importance because in the current era in which news spreads as it happens through the Internet and social media networks, investors, society, and governments are increasingly demanding that organisations be accountable to 
stakeholders, not merely shareholders, and be transparent about their activities (Abeysekera, 2013).

Oprişor (2014) noted that the utility of an "integrated report" is greater given the fact that it offers a balanced view on the entire entity. However it should be noted that IR in itself cannot realise the benefits. According to Abeysekera (2013), though IR has the potential to make accountability and performance in an organisation transparent, however the practical realisation depends on the ethical qualities (such as honesty, fairness) embedded in the organisation's values being upheld. Furthermore, Cheng et al. (2014) asserted that the ability of IRto play a role in accounting for value creation is not dependent on how effective organizations are in adopting the technical aspects, but rather on their ability to stimulate new thinking and action toward major business model adaptation. Thus the benefits of IR should be considered contextually.

\subsection{Integrated reporting framework in Malawi}

\subsubsection{Companies Act}

Performance reporting of companies in Malawi is generally regulated by the Companies Act, 1984, however the Act is old and in need of revision and upgrading (ROSC, 2007b) in line with modern environment. The Act does not provide for IR, it simply and explicitly provides for preparation and presentation of the income statement, statement of financial position, statement of cash flows, relevant explanations of company's operations and transactions, directors' report and auditor's report. ROSC (2007b) found the Act as one of the key obstacles to corporate governance in Malawi. Thus presently the Act is not an effective tool to the promotion of IR in the country.

\subsubsection{Code of Corporate Governance}

The code of best practice in corporate governance in Malawi - the Malawi Code II, makes provisions for IR for Malawian companies. Basically the Code's "sector guidelines for listed companies" are mandatory for all listed companies (Institute of Directors of Malawi, 2011). Generally the guidelines require the listed companies to clearly specify the provisions that have not been adhered to with clear reasons for non-compliance in their annual report (Institute of Directors of Malawi, 2011). Furthermore appeals to the Malawi Stock Exchange to act as the main custodian of the guidelines and to include compliance to them as part of the listing requirements (Institute of Directors of Malawi, 2011).

The Malawi Code II makes both general and specific provisions with regard to IR. According to this paper the "general provisions" are the indirect or general stipulations that give context to IR, whereas the "specific provisions" are the direct or explicit IR provisions. The following are the important general provisions contained in the Malawi Code II:

1. The listed companies are required to ensure best coordination of interests among various stakeholders (i.e. shareholders or investors, management, employees, suppliers, creditors, customers and local communities). 
2. The listed companies are required to conduct their profit-pursuing activities in a sustainable and responsible manner with great awareness of their social responsibilities, and with great transparency and fairness in accordance with market principles, while accepting accountability to shareholders and investors as well as to the entire community.

3. The listed companies are required to conduct their operations in a manner that meets existing needs without compromising the ability of future generations to meet their needs. The Code elucidates this point to mean that the companies must have regard for the impact that its operations have on the environment, economic and social life of the community in which it operates. The companies are as a result expected to report on how they have both positively and negatively impacted on the environment and the economic and social life of the community in which they operate and how they believe they can improve the positive and eradicate or lessen the negative aspects in the coming year.

4. The listed companies are required to consider making regular, timely, balanced and understandable statements about their activities, performance and future prospects.

With regard to the specific provisions, the review of the Malawi Code II revealed that the word "Integrated Reporting" is mentioned two times only as follows:

1. Under the roles of the board, stating that the board should: "Ensure that the integrated reporting by the organisation is accurate and truthful, at the time of disclosure." (Page 13). Accordingly the Code assigns the responsibility of ensuring the integrity of IR to the board.

2. As one of the main thematic headings of the Code. Under this heading which is called "Integrated reporting and auditing" there is only a single statement linked to IR and the rest are typical financial reporting and external auditing guidelines. The IR linked statement simply states that "sustainability reporting and disclosure should be integrated with the organisation's financial reporting."(Page 26). The review of the entire Code indicated that it simply made reference of "sustainability reporting" this once; nowhere else is it mentioned or defined.

The review also revealed that the Code does not make mention of or reference to an "integrated report". All in all the review indicated that the IR provisions were very few and less detailed and may not be capable of greatly promoting IR within the country. Thus the study recommends upgrading of the Code with regard to IR. A leaf may be borrowed from other Codes such as the King Code of Corporate Governance of South Africa that provides clear guidelines with regard to IR generally and preparation of integrated report. 


\subsubsection{Listing requirements}

A review of the Malawi Stock Exchange (MSE) listing requirements revealed that they do not make mention or reference to IR or integrated report; however they generally "encourage" good corporate governance practices in the listed companies along the lines of Cadbury and King Reports (Malawi Stock Exchange, 2008). Precisely, the listing requirements state that besides complying with the Companies Act, listed companies must disclose in their annual financial statements the "Code of corporate practices and conduct commenting on the extent of their compliance or non-compliance with the Code of Corporate Practices and Conduct contained in the Cadbury or King Reports on Corporate Governance". They further stipulates that this "statement may be contained in a separate section of the annual report and need not be audited".

The Cadbury report does not make provisions for IR; however the King Code of corporate governance for South Africa 2009 makes extensive provisions on IR. The King Code advocates the preparation and presentation of "integrated report" by the companies that should give sufficient information on how the company has both positively and negatively impacted on the economic life of the community in which it operated during the reporting year which may be categorised as environmental, social and governance issues. Furthermore it requires the board of directors to state in the integrated report how it believes that in the coming year it can improve the positive aspects and eradicate or ameliorate the negative aspects. It assigns to the board of directors the responsibility of ensuring the integrity of the company's integrated report that should be presented every year.

Unlike the provision of the MSE listing requirements which state that the statement of compliance "need not be audited", the King Code requires assurance on same. Besides, the Code charges the audit committee to oversee IR by:

- Having a regard to all factors and risks that may impact on the integrity of the integrated report.

- Reviewing and commenting on the financial statements included in the integrated report.

- Reviewing the disclosure of sustainability issues in the integrated report to ensure that it is reliable and does not conflict with the financial information.

- Recommending to the board the engagement of an external assurance provider on material sustainability issues.

The Code recognises that individuals today are the indirect providers of capital as such integrated reports should give the readers the forward-looking information they want, noting further that today's stakeholders also want assurance on the quality of this forward looking information. It is believed that by:

"issuing integrated reports, a company increases the trust and confidence of its stakeholders and the legitimacy of its operations. It can increase the company's business opportunities and 
improve its risk management. By issuing an integrated report internally, a company evaluates its ethics, fundamental values, and governance, and externally improves the trust and confidence which stakeholders have in it”. (Institute of Directors in Southern Africa, 2009)

The King Code's provisions on IR as shown are extensive; however their compliance by the Malawian listed companies may be negatively impacted by the MSE listing requirements' seeming lack of strong emphasis on the importance of corporate governance generally. This lack is manifested in a number of ways. For instance the word "corporate governance" is mentioned only two times in the entire document. Furthermore the requirements use words like "encourage" and "commenting" in referring to the need for compliance with corporate governance and in making disclosure of the same in annual report. Besides, auditing of the statement of compliance is entirely option. In view of this, the listing requirements need revision and updating with regard to corporate governance generally and more specifically to IR.

All in all, the IR framework in Malawi seems underdeveloped. The framework seems to be largely based on the Malawi Code II that lacks reasonable details with respect to IR hence in need of upgrading. Furthermore, although the Malawi Code II's Sector Guidelines for Listed Companies were given to the custody of the MSE, the listing requirements do not reflect the same and this has the potential to create uncertainty to the preparers of annual reports for the listed companies, hence there must be harmonisation.

\section{Research methodology}

\subsection{Sampling}

The study focused on the listed companies as such all companies listed on the Malawi Stock Exchange (MSE) comprised the population of the study. There are fourteen companies listed on MSE (see TABLE 1). Since the study aimed to evaluate the level of IR in Malawi, the focus was on Malawian companies (i.e. those whose primary operating environment is Malawi);as a result, Old Mutual Limited was excluded from the sample. Further to that since the study used the secondary data from the published annual reports of the listed companies, Blantyre Hotels Limited was also excluded from the sample due to unavailability of a published annual report. Hence the sample of the study was made up of twelve (12) companies representing about $85 \%$ of the listed companies. The sampled companies were randomly assigned alphabet letter code of $\mathrm{A}$ to $\mathrm{M}$. 
Table 1. List of companies listed on MSE and their sectors

\section{No Name of the companies Industry/ Sector}

1. Blantyre Hotels Limited ${ }^{*} \quad$ Tourism
2. First Merchant Bank
Banking

3. Illovo Sugar

Agro-processing

4. MPICO Limited

Property Development

5. National Bank of Malawi

Banking

6. NBS Bank

Banking

7. NICO Holdings Limited

Financial

8. National Investment Trust Limited Investment Trust

9. Press Corporation Limited Conglomerate

10. Real Insurance Limited Insurance

11. Standard Bank Banking

12. Sunbird Tourism Limited Tourism

13. Telekom Networks Limited Telecoms

14. Old Mutual Limited* Financial

(Source: Malawi Stock Exchange)

*Companies excluded from the sample

\subsection{Data collection and analysis}

Consistent with other related studies (Dumitru et al., 2013; du Toit et al., 2014); content analysis was employed to in collection of the data from the 2013 annual reports of the 
sampled listed companies. Analysis was made of the disclosures other than the financial statements (i.e. the statement of comprehensive income, statement of financial position, statement of changes in equity, statement of cash flows and notes to the accounts) as these mandatory in compliance to the requirements of the international financial reporting standards. A disclosure framework was used in order to evaluate the level of IR by the sampled listed companies.

\subsubsection{Development of the disclosure framework}

Consistent with du Toit et al. (2014), the disclosure framework for the study did not take full cognisance of the 2013 IR Framework of the International Integrated Reporting Council (IIRC), as it was published after the drafting of all the 2013 annual reports of the listed companies. The framework was thus developed based on the framework used by du Toit et al. (2014) in a similar study and the integrated report template proposed by Abeysekera (2013) (see TABLE 2). These were ideal to this study as they are all based on the conceptual model premised on the King Report on Governance for South Africa. As indicated already the Malawian listed companies are expected to comply with the same.

Table 2. du Toit et al. (2014)'s Disclosure Framework and Abeysekera (2013)'s IR Template

\begin{tabular}{|c|c|}
\hline $\begin{array}{l}\text { Disclosure Items used in du Toit et al. } \\
\text { (2014) }\end{array}$ & $\begin{array}{l}\text { Integrated Report headings proposed by } \\
\text { Abeysekera (2013) }\end{array}$ \\
\hline $\begin{array}{l}\text { 1. Ethical Leadership and Corporate } \\
\text { Citizenship } \\
\text { 2. Boards, Directors and Remuneration } \\
\text { a. Board Independence } \\
\text { b. Reporting on individual directors } \\
\text { c. Board Performance } \\
\text { d. Board Committees } \\
\text { e. Director's Remuneration } \\
\text { 3. Audit Committees } \\
\text { a. Finance Competence } \\
\text { b. Audit Committee Performance } \\
\text { 4. Governance of Risk } \\
\text { a. Risk disclosure of unexpected or current } \\
\text { risks threatening the long-term sustainability }\end{array}$ & $\begin{array}{l}\text { 1. Organisation's Vision } \\
\text { 2. Organisation's Values } \\
\text { 3. Organisation's Context } \\
\text { 4. Financial capital (eg intangible, } \\
\text { non-current assets, short-term loans) } \\
\text { 5. Intellectual capital (eg intellectual } \\
\text { capital, culture, processes, branding } \\
\text { building, customers) } \\
\text { 6. Environmental capital (eg material, } \\
\text { energy, gas and water) } \\
\text { 7. Social capital (eg equitable } \\
\text { employment, training and development and } \\
\text { health and safety) } \\
\text { 8. Governance (eg independent directors, } \\
\text { audit committee etc) }\end{array}$ \\
\hline
\end{tabular}


of the company

b. Effectiveness of the risk management processes.

5. Compliance with Laws, Codes, Rules and Standards

6. Internal Audit

a. Internal Audit Function

b. Internal Controls

7. Governing Stakeholder Relationships

a. Nature of dealings with stakeholders

b. Outcomes of these dealings.

8. Integrated Reporting and Disclosure

a. Financial Disclosure

b. Sustainability Disclosure

c. Sustainability Assurance

d. Summarised Integrated Report

9. Integrated Reporting Philosophy

a. General impression of how the company reacted to good integrated reporting

The two lists of items were combined to produce a disclosure framework presented in TABLE 3. It can be noted that items 4 to 8 proposed by Abeysekera (2013) were not explicitly imported to the disclosure framework as the rest. This was so because they are covered within the following items: corporate citizenship, compliance with laws, codes, rules and standards, boards, directors, audit committees and integrated reporting and disclosures. Thus twenty five (25) items of disclosure comprised the disclosure framework. 
Table 3. The Disclosure Framework For the Study

1. Organisation's Vision

2. Organisation's Values

3. Organisation's Context

4. Ethical Leadership and Corporate Citizenship

5. Boards, Directors and Remuneration

a. Board Independence

b. Reporting on individual directors

c. Board Performance

d. Board Committees

e. Director's Remuneration

6. Audit Committees

a. Summary of its role

b. Details of its composition

c. Number of meetings and activities

d. Finance function's competence

7. Governance of Risk

a. Risk disclosure of unexpected or current risks threatening the long-term sustainability of the company

b. Effectiveness of the risk management processes.

8. Compliance with Laws, Codes, Rules and Standards

9. Internal Audit Function

a. Effectiveness of internal Controls

b. Internal Audit function

10. Governing Stakeholder Relationships

a. Nature of dealings with stakeholders 
b. Outcomes of these dealings.

11. Integrated Reporting and Disclosure
a. Financial Disclosure
b. Sustainability Disclosure
c. Sustainability Assurance
d. Summarised Integrated Report

12. Integrated Reporting Philosophy

a. General impression of how the company reacting to good integrated reporting

\subsubsection{Measurement of integrated reporting}

The level of IR by the sampled listed companies was measured by Integrated Reporting Index (IRI). The annual reports were analysed and a "1" was assigned when an item on the disclosure framework (see TABLE 3) is disclosed and a " 0 " when it is not disclosed in the annual reports. The scoring methodology is consistent with other related annual report disclosure studies (Tsamenyi et al., 2007; Hossain, 2008; Bhasin, 2012; Biobele et al., 2013; Lipunga, 2014). Sinceneed to prepared "integrated report" is not explicitly given in the Malawi Code II, no company was expected to prepare a standalone integrated report. Thus evaluation was made on the narratives of annual reports.

Consistent with other annual report corporate governance disclosure studies (Boolaky, 2011; Lipunga, 2014), the IRI was calculated using the following formula:

$$
I R I=\sum_{i=1} \frac{d i}{n}=\frac{T S}{M}
$$

Where:

$$
\begin{aligned}
& I R I=\text { Integrated Reporting Index } \\
& d i=1 \text { if item iis disclosed; } 0 \text { if item } i \text { is not disclosed } \\
& n=\text { number of items } \\
& T S=\text { Total Score } \\
& M=\text { Expected Maximum Score }
\end{aligned}
$$

Thus, the expected maximum score for each sampled company was 25 , since there are 25 items of disclosure. The expected maximum IRI score was " 1 " and with a minimum of " 0 ". As such a score by a sampled company of 1 or closer to it suggested high level of IR by the 
company, otherwise a score of "0" or closer to it, suggested low level adoption of the concept.

On the other hand an Integrated Reporting Gap (IR Gap) was calculated using the following formula consistent with Boolaky (2011) and Lipunga (2014):

$$
\text { IR Gap }=1-I R I
$$

Where:

IR Gap = Integrated Reporting Gap

$I R I=$ Integrated Reporting Index

Since the expected maximum score is 1 , the IR gap is thus obtained by subtracting the actual IR score from 1 (Boolaky, 2011). Consequently the closer the IR Gap is to zero (0) the better the level of the IR in annual reports of the sampled companies.

\section{Results and discussion}

This section provides the results of analysis of the data. It begins by presenting the results and discussion of the types of narrative reports contained within the annual reports of the sampled companies and their frequencies. Thereafter it gives the IR scores and finishes with a look at the application of the "comply or explain" basis for the code of corporate governance.

\subsection{Typical narrative reports within the annual reports of sampled companies}

As already indicated it was expected that no company will present a standalone integrated report as the Malawi Code II does not explicitly require it nor mentions it. Accordingly the analysis confirmed the same. All the sampled companies did not present an integrated report or have it prominently presented within the narrative reports within the 2013 annual reports. As is exhibited in TABLE 5A, the annual reports of the sampled companies contained narrative reports that may be grouped into four namely: Chairman's report, Chief Executive Officer (CEO)'s (or Managing Director's) report, Director's reports and other reports (i.e. reports that were covering issues such as corporate social responsibility, corporate governance and corporate profile etc). It must be noted that the auditor's report was not considered in accordance with the objectives of the study.

The analysis (see TABLE 5A) revealed that all the 12 (100\%) sampled companies presented the Director's report, $10(83 \%)$ presented a chairmen's report, $10(83 \%)$ other reports while 9 (75\%) presented the CEO's report. It is not surprising that all the companies presented the Director's report because unlike the other types of reports, it is specifically required by the Companies Act, 1984 and it is also mentioned three times in the Malawi Code II as an important medium of communication by the board of directors. This may suggest that if the integrated report can be explicitly required by regulations, all companies are likely to present it. 


\section{Macrothink}

Table 5A. Typical Reports Presented in Annual Reports

\begin{tabular}{lll}
\hline & No. of Companies & $\%$ \\
\hline Chairman's report & 10 & $83 \%$ \\
\hline CEO's report & 9 & $75 \%$ \\
\hline Director's report & 12 & $100 \%$ \\
\hline Other reports (CSR, CG**, CP*** etc) & 10 & $83 \%$ \\
\hline$*$ Corporate Social Responsibility**Corporate Governance & \\
\hline$* * *$ Corporate Profile & & \\
\hline
\end{tabular}

Furthermore, TABLE 5B indicates that eight companies (67\%) presented all the four narrative reports while one $(8 \%)$ presented three of the four and the remaining three $(25 \%)$ presented two of the four. The analysis suggests that the sampled companies are generally aware of importance of narrative reporting in their annual reports and are making using various types of reports within it. This awareness may be extended in the promotion and implementation of integrated reporting. As it has already been indicated the IIRC IR framework provide that an integrated report may be prepared either a standalone report or be included as a distinguishable, prominent and accessible part of another report or communication (IIRC, 2013). Thus MSE, IOD-Malawi and other promoters of corporate governance should consider encouraging the companies to issue integrated reports within annual report or within in other reports as a step towards full IR.

Table 5B. Report presentation frequency

\begin{tabular}{|c|c|c|}
\hline & No. of Companies & $\%$ \\
\hline All four reports & 8 & $67 \%$ \\
\hline Three of the four & 1 & $8 \%$ \\
\hline Two of the four & 3 & $25 \%$ \\
\hline One of the four & 0 & $0 \%$ \\
\hline None & 0 & $0 \%$ \\
\hline TOTAL & 12 & $100 \%$ \\
\hline
\end{tabular}




\subsection{Integrated Reporting scores}

Since no company presented an integrated report as expected, the level of IR of the sampled listed companies was evaluated by analysing the typical reports presented in TABLE 5A. The study uses three IR score levels in presenting results of analysis namely: individual company scores, overall (average) scores and individual item scores. As already noted, IRI closest to 1 signify high level of IR and while a better IR Gap should be closer to 0 .

\subsubsection{Individual Company and Overall IRI scores}

Figure 1 presents individual company IR scores and the overall (average) score and their corresponding IR Gaps. The Figure indicated that the IRI that was closest to 1 was 0.64 scored by Company I, suggesting that it disclosed in its 2013 annual report $64 \%(n=16)$ of the items on the IR disclosure framework. On the other hand the lowest IRI was 0.16 scored by Company $\mathrm{C}$, suggesting that the company disclosed only $16 \%(\mathrm{n}=4)$ of the items of disclosure. Respectively these two companies had the best (0.36) and worst (0.84) IR Gaps. Furthermore, Figure 1 shows that only five companies (about 42\%)disclosed at least half of the items(i.e. by their scores were of at least 0.5 )whereas the majority (i.e. seven or about $58 \%$ ) disclosed less than half.

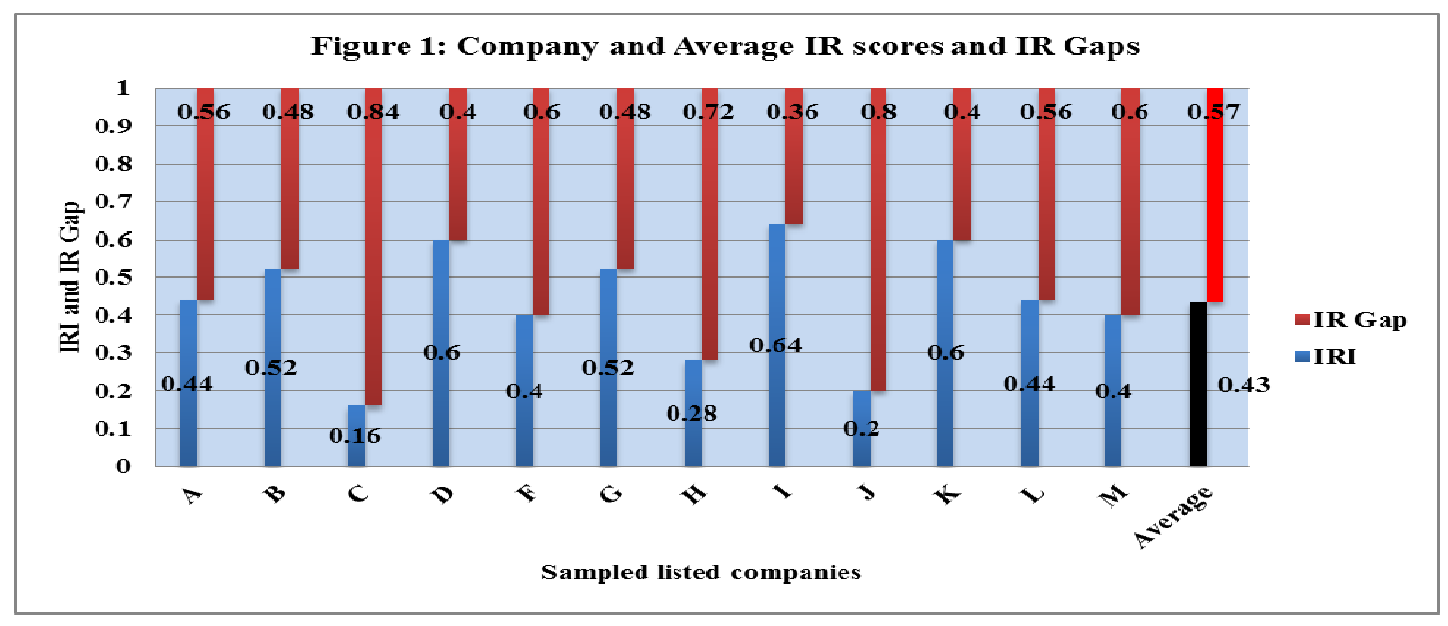

The overall IR score for the sampled companies was 0.43 as exhibited by the average score on Figure 1. Accordingly the score suggests that on average $43 \%$ (or $n=10$ ) of the items on the IR disclosure framework were actually disclosed. The overall score indicates some progress by the listed companies towards adoption of IR philosophy in presenting their annual reports. On the other hand it reveals a bigger average IR gap of 0.57 that needs to be filled towards achieving full IR. Considering further that the IR disclosure framework adopted by the study was not as comprehensive as the IIRC framework, the gap is likely much wider if the latter can be used. This further indicates that more promotional work is needed in order to stimulate IR in Malawi. It is thus incumbent on the Institute of Directors of Malawi (IOD-Malawi) and the Malawi Stock Exchange (MSE), as principal promoter of corporate governance in Malawi to strategize on their promotional work, by among other things, incorporating IR fully in the Code of corporate governance and the listing requirements. This incorporation exercise would need to take into consideration the 
provisions of IIRC IR framework to ensure that Malawi is in tandem with international best practice.

Furthermore the IOD-Malawi and MSE together with other professional bodies in Malawi such as Institute of Chartered Accountants in Malawi (ICAM) and relevant stakeholders should step up their efforts in lobbying the government of Malawi to revise the Companies Act, for it to be in harmony with recent developments. As found by ROSC (2007a) and ROSC (2007b) the piece of legislation is old and an obstacle to corporate governance and financial reporting in Malawi. Accordingly it should be reviewed to provide for up-to-date requirements, and to ensure that there is room/flexibility to incorporate updates as they arise (ROSC, 2007a).

\title{
4.2.2 Disclosure Item IRI score level
}

This section presents the analysis of individual item IR scores in descending order. TABLE 6A gives the disclosure items that obtained maximum score of 1 . As is exhibited on the TABLE 6A, only three (3) out of twenty-five (25)scored 1, these are "organisation's context", "compliance with laws, codes and standards" and "financial disclosure". The maximum scores indicate that these three items were disclosed by all the twelve sampled companies in their annual reports. The scores suggest that all the sampled companies endeavoured to give some information about their operating environment, gave a statement that they are complying with relevant regulatory instruments and provided some analysis of financial performance and position of the companies over and above the disclosures required by the accounting standards.

Table 6A. Items disclosed at Maximum level (IRI = 1)

\author{
Organisation's Context \\ Compliance with Laws, Codes, Rules and Standards
}

Financial Disclosure

TABLE 6Bon the other hand, indicates that two items obtained the second highest score of 0.83 , these are "board independence" and "summary of audit committee role". Accordingly, these items were disclosed by ten sampled companies. It is worth noting that it seems that the important role of the audit committee as well as the independence of the board is well recognised the bigger majority of the companies. 


\section{$\triangle$ Macrothink}

Table 6B. Items disclosed at 0.83 level

\section{Board Independence}

Summary of its [audit committee] role

TABLE 6C shows items that scored third highest (0.75). As is exhibited five items scored at this level. These include: ethical leadership and corporate citizenship, board committees, number of meetings and activities [of audit committee], sustainability disclosure and general impression of how the company reacting to good integrated reporting. An item worth noting is "general impression of how the company reacting to good integrated reporting". The "general impression" in this study does not necessarily mean the companies were fully presenting information as per the IR concept, but they showed willingness to provide more non-financial information. According to Ioana and Adriana (2013) there are three main stages in the evolution of integrated reporting, namely: (1) non-financial reporting initiatives, (2) sustainability era, and (3) revolution of integrated reporting. Accordingly, though the nine companies were yet to reach the "revolution of integrated reporting" stage, they however gave the impression that they appreciate the importance of providing more non-financial information beyond the requirements of the Companies Act. Thus it may be assumed that what is lacking for these nine companies may bea strong IR framework.

On the other hand three companies $(\mathrm{C}, \mathrm{H}$ and $\mathrm{J})$ gave a poor impression. An analysis of the items they disclosed indicated that they were focusing concentrating on popular items generally which are "Organisation's Context", "Compliance with Laws, Codes, Rules and Standards", "Financial Disclosure" and "Board Independence". Thus they were not go beyond the "common".

Table 6C. Items disclosed at 0.75 level

1. Ethical Leadership and Corporate Citizenship

\section{Board Committees}

3. Number of meetings and activities [of audit committee]

\section{Sustainability Disclosure}

5. General impression of how the company reacting to good integrated reporting

TABLE 6D gives the items scoring between 0.58 and 0.5.As exhibited there were two items in this category namely:"Nature of dealings with stakeholders"and "Organisation's Vision or mission". It is worth noting that only half of the sampled companies disclosed their vision or mission while a simple majority disclosed the nature of the dealings with its stakeholders. 
Table 6D. Items disclosed at $0.58-0.5$

\begin{tabular}{lc}
\hline & IRI \\
\hline Nature of dealings with stakeholders & 0.58 \\
Organisation's Vision or mission & 0.50 \\
\hline
\end{tabular}

TABLE 6D together with the TABLEs above indicates the twelve items that scored 0.5 or above. Thus only about $48 \%$ of the items on the IR disclosure framework were disclosed by at least half of the sampled listed companies, and the majority (about 52\%) were disclosed by less than 6 companies. Below are TABLEs $\mathbf{6 E}$ and $\mathbf{6 F}$ exhibiting these poorly disclosed items.

TABLE 6E gives the disclosure items that scored poorly but were disclosed by at least one of the sampled companies. They include "Organisation's Values" (disclosed by five companies), "Effectiveness of the risk management processes" (disclosed by 4 companies), "Internal Controls" and "Outcomes of these dealings"(each disclosed by 3 companies) and "Board Performance" (disclosed by a single company). A notable item on this category was "board performance", only a single company disclosed about the board evaluation contrary to the Malawi Code II that explicitly requires the Board of any listed company to annually evaluate the board's performance, its processes and the mixture of experience and skills. Furthermore, it requires the evaluation to be reported in the Director's or Annual Report.

Table 6E. Items scoring less than $0.5-0.08$

\begin{tabular}{lc}
\hline & IRI \\
\hline Organisation's Values & 0.42 \\
\hline Effectiveness of the risk management processes. & 0.33 \\
\hline Internal Controls & 0.25 \\
\hline Outcomes of these dealings. & 0.25 \\
\hline Board Performance & 0.08 \\
\hline
\end{tabular}

Finally TABLE 6F presents items that were not disclosed by any of the twelve sampled companies. The TABLE indicates that eight items (32\%) scored zero. The notable ones include "report on individual directors" contrary to Malawi Code II that requires the Board of any listed company to annually evaluate the Chairman and other Members of the Board and the chief executive officer. The other notable item is "director's remuneration". The Code 


\section{Macrothink}

Journal of Management Research

ISSN 1941-899X

2015, Vol. 7, No. 3

requires disclosures at least on an aggregate basis of remuneration, bonuses and other benefits received by members of the boardin directors' or annual report. The companies were only disclosing the same within the notes to the accounts which is in accordance with accounting rules.

Table 6F. Items disclosed at 0 level

1. Reporting on individual directors

2. Director's Remuneration

3. Details of its [audit committee]composition

4. Finance function's competence

5. Risk disclosure of unexpected or current risks threatening the long-term sustainability of the company

6. Internal Audit function

7. Sustainability Assurance

8. Summarised Integrated Report

Furthermore, the details of the composition of the audit committee were another notable miss. Companies were simply disclosing the names of the members, attendance to the meeting without disclosing skills and experiences that may be of much importance. Furthermore, the King Code requires the audit committee to satisfy itself of the expertise, resources and experience of the company's finance function and the results of such a review to be disclosed in the integrated report, as the score suggests no single company made such disclosure.

\subsection{Application of the “comply or explain” basis}

The Malawi Code II is premised on "comply or explain" basis. Accordingly companies are supposed to state in annual or directors' reports whether the Code has been adhered to or, if not, explain with reasons in what respects it has not been adhered to. Thus both compliance and non-compliance must both be appropriately disclosed. Analysis of the annual reports indicated that no company made a disclosure of any non-compliance which should suggest full compliance. On the other hand as the individual items scores suggested, to a larger extent the disclosure of the specifics of compliance were hardly made, however companies were simply making general statements of compliance and or commitment to the same 
unsupported by disclosures. The following are examples of such unsupported general statements extracted from the annual reports of four sampled companies:

"The directors are committed to the implementation of, and endorse the applicable codes, guidelines, legislation, regulations and standards in terms of corporate governance."

"The board of ... subscribes to the principles of openness, integrity and accountability as set out in the Malawi Corporate Governance Code, The Cadbury Report and the King Reports and is thus committed to good corporate governance...."

"Compliance with applicable legislation, regulations, standards and codes remains an essential characteristic of the Group's culture."

"The board complies with the major principles of modern corporate governance as contained in the Code of Best Practice for Corporate Governance in Malawi (The Malawi Code II)."

This kind of reporting may diminish the fundamental reporting qualities of relevance to users and faithful representation that can be verified and understood by stakeholders (Abeysekera, 2013). It appears there is need for clarity by the authorities of what compliance and non-compliance with the Code entails and the required disclosures on the same in the annual reports or any other means of communication as should be with reference to the comply or explain basis. The IOD-Malawiand MSE need therefore to provide proper guidance the companies of the nature of the presentation of disclosures and subsequently monitor implementation of the same.

It must also be noted that companies themselves are morally obligations to provide adequate information to stakeholders. Furthermore, itis also to their best interest in global village to meet the international standards to be competitive. As posited by Deloitte (2011)the knowledge and insight acquired through an IR process can be significant; as a result forward-thinking organisations will get ahead of the curve. Deloitte (2011) noted that progressive organisations should consider moving towards IReven prior to the establishment of any formal requirements. It was postulated that:

"The potential advantages to be gained in terms of managing risk, maximising value, obtaining competitive advantage, attracting capital, improving compliance, and enhancing stakeholder relations increase significantly for those with the wherewithal to lead rather than follow. In fact, there is much to be gained from adopting a business model and reporting framework that is more closely aligned with sustainable and socially responsible strategies to manage both our natural and human resource base, future business growth will likely depend on this alignment."Deloitte (2011)

\section{Conclusion}

The modern society demands greater transparency, accountability and responsibility from organisations (Institute of Directors of Malawi, 2011). As a result companies are under pressure to provide more and more information both financial and non-financial in relation to their performance. This is a departure from the traditional financially biased reporting. Ioana and Adriana (2013)argued that non-financial information is as much valuable as the financial 
one.Integrated reporting is consequently emerging as a sure answer to the demands of the modern society. As a result, progressive organisations should be moving forward to IRevenprior to the establishment of any formal requirements (Deloitte, 2011). The study has endeavoured to evaluate the IR framework in Malawi and the current status of IR implementation among the listed companies. The study employed content analysis to evaluate the 2013 annual reports of the sampled listed companies based the IR disclosure framework which was developed based on the du Toit et al. (2014) and Abeysekera (2013) studies.

The results of analysis suggest some progress towards the implementation of IR indicated by an average IRI of 0.43 and on the other hand revealing a bigger IR gap of 0.57 that needs filling. Furthermore it was found that the IR framework is based on the Code of Corporate Governance that contains less detailed guidance with regard to IR. Furthermore the Companies Act is out-dated and an obstacle to corporate governance and financial reporting (ROSC, 2007a; ROSC, 2007b), besides, the MSE listing requirements lack strong and direct emphasis on corporate governance generally. Thus the study recommends revision and up grading of the Malawi Code II, Companies Act and MSE listing requirements.

The study provides practical insight on the areas that need improvements in the promotion of IR in Malawi both to the regulators, promoters and the preparers of annual reports. It contributes to understanding of the current IR framework and the extent of IR in annual reports of listed companies in Malawi. Furthermore, Oprişor (2014) stated that IR is a relatively new concept and the research within this field is still in a complex developmental process. The current study promotes it development. The study further adds to extant literature on IR in developing countries and serves as future reference point.

The study has some limitations. It evaluated annual reports for a single year and only of listed companies. Future study should endeavour to do a longitudinal evaluation to appreciate the progress over the years and expand the sample that incorporates unlisted companies in order to have a comprehensive picture. The study also used a disclosure framework that did not take full consideration of the provisions of the IIRC framework. Future studies should consider developing the evaluation tool that fully incorporates its requirements.

\section{Reference}

Abeysekera, I. (2013). A template for integrated reporting. Journal of Intellectual Capital, 14(2), pp. 227-245. http://dx.doi.org/10.1108/14691931311323869

Ávila L. V., Hoffmann C., Corrêa A. C., Madruga L. R. D. R. G., Júnior V. F. S., Júnior A. F. D. S., and Zanini R. R. (2013). Social Responsibility Initiatives Using ISO 26000: An Analysis from Brazil Environmental Quality Management / Winter 2013 / 15 - 30 / DOI 10.1002/tqem.

Bhasin, M. L. (2012). Voluntary Corporate Governance Disclosures: An Exploratory Study. International Journal of Contemporary Business Studies, 3(9), 6-26. 
Biobele, B. S., Igbo I. E. and John, E. F. (2013). The Significance of International Corporate GovernanceDisclosure on Financial Reporting in Nigeria. International Journal of Business and Management, 8(8), 100-106. http://dx.doi.org/10.5539/ijbm.v8n8p100

Boolaky, P. K. (2011), Global Reporting Initiatives (G3), Standard Disclosures for Human Resource Practices:Compliance and Determinants in the Financial Services Sector: Europe, Asia and Others. Academy of Taiwan Business Management Review, pp. 1-15. Available http://www98.griffith.edu.au/dspace/bitstream/handle/10072/45389/78025_1.pdf?sequence=1

Cheng M., Green W., Conradie P., Konishi N. and Romi A. (2014).The International Integrated Reporting Framework: Key Issues and Future Research Opportunities. Journal of International Financial Management \& Accounting, 25(1), 90-119. http://dx.doi.org/10.1111/jifm.12015

Churet C., RobecoSAM, \& Eccles R. G. (2014).Integrated Reporting, Quality of Management, and Financial Performance. Journal of Applied Corporate Finance, 26(1).

Deloitte. (2011). Integrated reporting: A better view?http://www.corpgov.deloitte.com/binary/com.epicentric.contentmanagement.servlet.Co ntentDeliveryServlet/CanEng/Documents/Financial\%20Reporting/Transparency/IntegratedR eporting_BetterView.pdf

Dumitru M., Glãvan M. E., Gorgan C. and Dumitru V. F. (2013). International integrated reporting framework: A case study in the software industry. Annales Universitatis Apulensis Series Oeconomica, 15(1), 24-39.

du Toit A., Steyn B., Pilley, A., \& Gweshe R. (2014). Insights into SOC Integrated Reporting Trends in South Africa. Available:http://www.nkonki.com/download.php?filename=administrator/media/uploads/idv4129529-62ed93c496f901de65ee73ca5764246b.pdf.

Eccles R. G., \& Saltzman D. (2011). Achieving Sustainability through Integrated Reporting. Stanford Social Innovation Review, 56-61.

Habidin N. F., Fuzi N. M, Desa A. F. N. C., Hibadullah S. N., \& Zamri F. I. M. (2012). Corporate Social Responsibility Practices (CSRP) and ISO 26000 Performance Efforts in Malaysian Automotive Industry. International Journal of Economics, Finance and Management, 1(1), 1-7.

Hossain, M. (2008). The Extent of Disclosure in Annual Reports of Banking Companies: The Case of India. European Journal of Scientific Research, 23(4), 659-680.

Institute of Directors of Malawi. (2011). The Malawi Code II: Code of Best Practice for Corporate Governance in Malawi, Sector Guidelines for Listed Companies. Retrieved from http://www.ecgi.org/codes/documents/sector_guidelines_listed_companies_malawi_10feb20 11_en.pdf 


\section{Macrothink}

Journal of Management Research ISSN 1941-899X 2015, Vol. 7, No. 3

Institute of Directors in Southern Africa. (2009). King Code of corporate governance for South Africa 2009.

Retrieved

fromhttp://c.ymcdn.com/sites/www.iodsa.co.za/resource/collection/94445006-4F18-4335-B7 FB-7F5A8B23FB3F/King_Code_of_Governance_for_SA_2009_Updated_June_2012.pdf

International Integrated Reporting Council (IIRC). (2013). The International <IR> Framework.

Availablehttp://www.theiirc.org/wp-content/uploads/2013/12/13-12-08-THE-INTERNATIO NAL-IR-FRAMEWORK-2-1.pdf

Ioana D. and Adriana T. (2013). New Corporate Reporting Trends: Analysis On The Evolution Of Integrated Reporting. The Journal of the Faculty of Economics - Economic, 1(1), 1221-1228. http://steconomiceuoradea.ro/anale/volume/2013/n1/129.pdf

Krzus M. P. (2011). Integrated reporting: if not now, when? IRZ, Heft 6, Juni 2011, pp. 271-276. Availablehttps://www.mikekrzus.com/downloads/files/IRZ-Integrated-reporting.pdf

Lipunga A.M. (2014). A Review of Disclosure Provisions in Malawian Codes of Corporate Governance. International Journal of Business and Social Science, 5(1), 246-256

Malawi Stock Exchange (2008).Listing requirements. Retrieved from http://mse.co.mw/rules/MALAWI\%20STOCK\%20EXCHANGE\%20LISTING\%20REQUIR EMENTS.pdf

Oprişor T. (2014). The integrated reporting framework: between challenge and innovation. Network Intelligence $\quad$ Studies, $\quad 1(3), \quad 85-94$. Availablehttp://www.nis.bxb.ro/Article/NIS_3_10.pdf

Reports on the Observance of Standards and Codes (ROSC). (2007a). Accounting and Auditing Malawi. Available: http://www.worldbank.org/ifa/rosc_aa_mwi.pdf

Report on the Observance of Standards and Codes (ROSC). (2007b). Corporate governance country assessment Malawi. [Online] Available: http://www.worldbank.org/ifa/rosc_cg_mwi.pdf.

Tsamenyi, M., Enninful-Adu, E., \& Onumah, J. (2007). Disclosure and corporate governance in developing countries: evidence from Ghana. Managerial Auditing Journal, 22(3), 319-334. http://dx.doi.org/10.1108/02686900710733170 